\title{
Optimized design and test for a pendulum suspension of the crop spray boom in dynamic conditions based on a six DOF motion simulator
}

\author{
Longfei Cui ${ }^{1,2}$, Hanping Mao ${ }^{1 *}$, Xinyu Xue ${ }^{2}$, Suming Ding ${ }^{2}$, Baiyu Qiao ${ }^{2}$ \\ (1. Key Laboratory of Modern Agricultural Equipment and Technology, Ministry of Education, Jiangsu University, Zhenjiang 212013, China; \\ 2. Nanjing Research Institute for Agricultural Mechanization, Ministry of Agriculture, Nanjing 210014, China)
}

\begin{abstract}
Spray deposit distribution from a field sprayer is mainly affected by the boom movements when the tractor is driven over a rough soil surface, the pendulum suspension that used to reduce and control the movement of spray boom by isolating the boom from vibrations of the tractor will directly enhance uniform deposition of chemicals. However, how to match the parameters of the suspension with the properties of the boom is the key problem. The dynamic rigid-flexible coupling model of the virtual prototype of the spray boom suspension system was established by using ADAMS and ABAQUS software. An optimization of the suspension parameters for a large spay boom was carried out based on the optimal Latin hypercube design, radial basis function neural network, and multi-objective genetic algorithm NSGA-II. After modified parameters of the suspension, the travel of the sprayer on a typical field motion track was simulated based on a six DOF motion simulator, and the dynamic behavior of the boom suspension was measured. The results show that RMS of the measured boom roll angle and the boom center displacement for optimized solution were reduced by $14.76 \%$ and $12.43 \%$ compared with the original suspension. Finally, the inertial measurement unit (IMU) was used to measure the movements of the sprayer vehicle during the pesticide application on the Hongze Lake Farm, the experiment of field condition reproduced by using the six DOF motion simulator, the standard deviation of the roll angle and vibration displacement for the optimized sprayer boom are only $0.6382^{\circ}$ and $62.279 \mathrm{~mm}$ respectively. The research provides theoretical basis and experimental method for parameter optimization of large scale boom suspension.
\end{abstract}

Keywords: boom sprayer, pendulum suspension, parameter optimization, spray boom movement, spray deposit distribution, six DOF motion simulator

DOI: $10.25165 /$ j.ijabe.20181103.3717

Citation: Cui L F, Mao H P, Xue X Y, Ding S M, Qiao B Y. Optimized design and test for a pendulum suspension of the crop spray boom in dynamic conditions based on a six DOF motion simulator. Int J Agric \& Biol Eng, 2018; 11(3): 76-85.

\section{Introduction}

To increase yield in agriculture, plants need to be protected against diseases and need to be provided with fertilizer. One of the most important methods to supply the plants with agrochemicals is by using spray boom ${ }^{[1,2]}$. Owing to large spray boom widths, flexible behavior of spray booms becomes important. When sprayer travels over undulating terrain, even small deformations of the structure can cause, by the large spray boom width, considerable displacements at the boom tips ${ }^{[3]}$. Lots of studies ${ }^{[4-7]}$ has shown the unwanted movements of boom, rolling, yawing and jolting, are caused by spray vehicle roll as it travels over undulating terrain, dramatically affect the spray distribution pattern. Theoretical studies, simulations and field experiments

Received date: $2017-08-17 \quad$ Accepted date: $2017-11-15$

Biographies: Longfei Cui, PhD candidate, Assistant Research Fellow, research interests: agricultural machinery system dynamics and control technology, Email: cuilong.fei@163.com; Xinyu Xue, PhD, research fellow, research interests: crop protection and machinery engineering, Email: 735178312@qq.com; Suming Ding, research fellow, research interests: pesticide application technology and plant protection machinery, Email: dsmchina@sina.com; Baiyu Qiao, MS candidate, research interests: crop protection and machinery engineering, Email: 992670374@qq.com.

*Corresponding author: Hanping Mao, PhD, Professor, research interests: modern agricultural equipment and facilities agriculture environmental control technology. Key Laboratory of Modern Agricultural Equipment and Technology, Ministry of Education, Jiangsu University, Zhenjiang 212013, China. Tel: +86-13511695868, Email: maohp@ujs.edu.cn. have indicated that due to spray boom movements, spray deposit distribution varies between 0 and $800 \%$. The most important movements, affecting the spray distribution pattern, are rolling (rotational motion around an axis along the driving direction) and vertical jolting in the vertical plane ${ }^{[8-10]}$.

In order to reduce the unevenness in spray deposit, the agricultural sprayers should have equipped with a vertical balancing system to attenuate roll and vertical jolt of the boom. Pendulum passive boom suspension is very popular equipped on $12-28 \mathrm{~m}$ long boom sprayer which keeps the boom at right angles to gravity by isolating the boom from vibrations of the tractor or trailer, induced by soil unevenness ${ }^{[11]}$. However, there is not a clear correlation between boom movements and the parameters of spray boom suspension. Therefore, through the establishment of rigid flexible coupling multibody dynamic model, we can study the dynamics behavior of the boom suspension system which has an important engineering value for improving the boom stability and damping effect of the suspension.

The boom movements mainly depend on the soil roughness and mechanical features of the sprayer (including features of boom suspension), especially these dynamic characteristics: velocity and dynamic features of the machine (stiffness, damping, moment of inertia).A number of published studies show that, under dynamic field conditions, a field sprayer gives much larger variations of spray distributions. Field measurements at the Federal Biological Research Centre Braunschweig (BBA) have shown the importance of the dynamic criteria. To avoid the effect of vehicle parameters, one solution is to use the motion simulator ${ }^{[12,13]}$. So a six DOF 
motion simulator was built and used for the dynamic characteristics optimization of boom suspension. A lot of dynamic field conditions can reproduce in the laboratory. It enables test conditions to be exactly the same for any machine tested, and observations to be made easily, reliably and with respect to fixed references.

Traditional suspension optimization is usually to parameterize the virtual prototype simulation model combined with experimental design analysis or optimization algorithm and make multiple simulation optimization, but its calculation is time-consuming and it is difficult to converge for the complex models ${ }^{[14,15]}$. Integrating the virtual prototyping and optimization algorithm by the Isight Multidisciplinary optimization platform, and building a neural network approximation model based on the radial basis function to describe the relationship between design variables and responses, then substituting the rigid coupling model simulation model to conduct the optimization when precision of neural network model is satisfied, all of which can improve the optimize efficiency significantly.

In this study, a multi-objective optimization of the pendulum suspension parameters was proposed based on the optimal Latin hypercube design (Opt LHD), the radial basis function neural network (RBFNN), and the multi-objective optimization genetic algorithm (MOGA). The aim is reducing unwanted sprayer boom movements such as boom rolling and vertical jolting. The spray boom was flexibly treated by using modal reduction method, and build a flexible-rigid coupling dynamics model of the pendulum boom suspension, the step response experiment of the suspension was carried out in the laboratory, and the correctness of the model was verified by comparing with the test results. The optimization objectives are minimizing the RMS of boom roll angle and vertical jolting displacement of the boom center. A neural network approximation model based on the radial basis function was trained to instead of simulation model, the suspension dynamic parameters (spring stiffness values and damping values of the suspension) were optimized by the multi-objective genetic algorithm to obtain the optimal combination of parameters of suspension and the boom suspension was tested under various working conditions on the motion simulator.

\section{Pendulum boom Suspension configuration and working principle}

\subsection{Suspension configuration}

As is shown in the Figure 1 for the structure of the pendulum suspension of a 28 meters long spray boom, support frame 1 is used to bear the gravity of the boom system and inertia load. The pendulum rod 2 is jointed with the support frame 1 in rotation $O$ through a bearing. The pendulum suspension mechanism is composed of pendulum rod 2 , center frame 3 , bracket 4 , vertical shock absorber 5 and lateral shock absorber 6 . The left side and right side of boom are connected with the center frame 3 by the rotating pairs, set point $P$ as the mass center of the spray boom (include left spray boom, center frame, and right spray boom), the center frame 3 can slide along the pendulum rod 2 . The bracket 4 is fixed the end of the pendulum rod 2. Vertical shock absorbers are articulated between the center frame 3 and the bracket 4 , to attenuate the fluctuation of the ground. Lateral shock absorber is articulated between center frame 3 and the support frame 1 . Because of the boundary from the suspension mechanism, the mainly movements of the boom in the vertical plane are the rolling around the rotation $O$ and the vertical vibration along the pendulum rod 2, the two kinds of the movements above are mutually coupled.

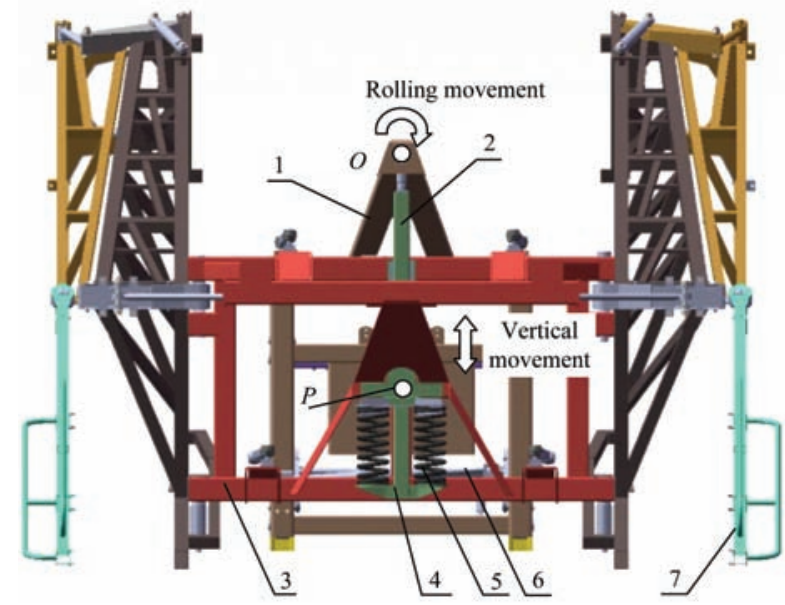

1. Support frame 2. Pendulum rod 3. Center frame 4. Bracket 5. Vertical shock absorber 6. Lateral shock absorber 7. Spray boom

Note: $O$ is rotation center of pendulum rod; $P$ is mass center of spray boom.

Figure 1 Structure of spray boom and pendulum suspension

\subsection{Working principle}

Two important reasons for suspending a spray vehicle boom are to reduce mechanical stress, and to provide a stable platform from which spray can be dispersed. A stable boom will give a more even coverage of spray and can also be mounted closer to the crop without fear of the boom tips striking the ground. The lower the boom, the less the spray is affected by the wind and so drift is reduced ${ }^{[16]}$. Pendulum boom suspension isolates the boom from high frequencies and transmits low frequencies but can dissipate, temporarily store and later return energy to the system. The boom stabilizing forces are generated in response to local relative motion, velocity and acceleration. The common suspension elements include springs, dampers and linkages.

The pendulum suspension is based on the pendulum theory and its mass center $P$ is always on the left or right of the vertical line below the $O$ point. Suppose that the angle between the pendulum rod $O P$ and the gravity line is $\theta$, the mass center of the boom will swing back and forth in the equilibrium position due to the restoring force provided by the gravity and spring force. The adjustable hydraulic dampers are installed between the frame and the pendulum. Due to the consumption of kinetic energy by the damper and friction, the boom will eventually return to balance position.

Previous work ${ }^{[17,18]}$ has shown that the dynamic characteristics of the boom suspension was mainly determined by the mass of the boom, moment of inertia and the coefficient of spring stiffness and damping of the suspension. For purpose of improving the vibration reduction effect and stability of suspension, the following issues are considered: modelling of the suspension, reasonable optimized the dynamic parameters of the spray boom suspension system such as spring stiffness $K_{1}$ and damping coefficient $C_{1}$ of the vertical shock absorbers, spring stiffness $K_{2}$ and damping coefficient $C_{2}$ of the lateral shock absorber.

\section{Flexible-rigid coupling dynamics model of the suspension}

\subsection{Suspension parameters determination}

The experimental subjects is the spray boom and its pendulum suspension in Figure 1, the shock absorbers used in the suspension consists of springs and viscous dampers, the damping characteristic of the damper was measured when removed from the suspension 
and by applying a constant force $D$ to the damper and measuring its rate of extension $\dot{X}$ on electromechanical universal material testing machine, $X$ was always within the range $\pm 0.03 \mathrm{~m} / \mathrm{s}$. Figure 2a shows a linear least squares line, relating the force applied to the damper to its rate of extension or contraction through the experimentally obtained points. The equation of the line can be given by

$$
|D|=|\dot{X}| \cdot C
$$

where, $C$ represent the coefficient of viscous damping for the damper, the experimentally obtained values by fitting the experimental data for $C_{1}$ and $C_{2}$ were $11389.7 \mathrm{~N} \cdot \mathrm{s} / \mathrm{m}$ and 5110 $\mathrm{Ns} / \mathrm{m}$ respectively. The coil springs belong to compression spring, whose stiffness coefficients are tested using a universal testing machine. By compressing spring uniformly, we can measure the relationship between compressing force and deformation and slope of the curve, then we get the stiffness coefficient $K_{1}$ is $25760 \mathrm{~N} / \mathrm{m}$ by calculating slope of tested curve (Figure $2 b$ ). By using an electronic scale, it is measured that the quality of the spray boom is $922.6 \mathrm{~kg}$. The inertia of spray boom around the mass center $I_{2}$ is $3.27 \mathrm{e} 4 \mathrm{~kg} \cdot \mathrm{m}^{2}$ calculated by using three-dimensional geometry model in SolidWorks, the main parameters for the boom suspension are shown in Table 1.

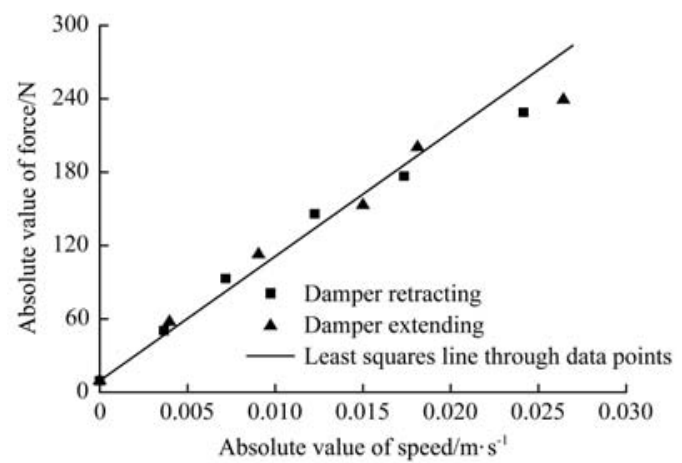

a. Damping coefficient test of the damper

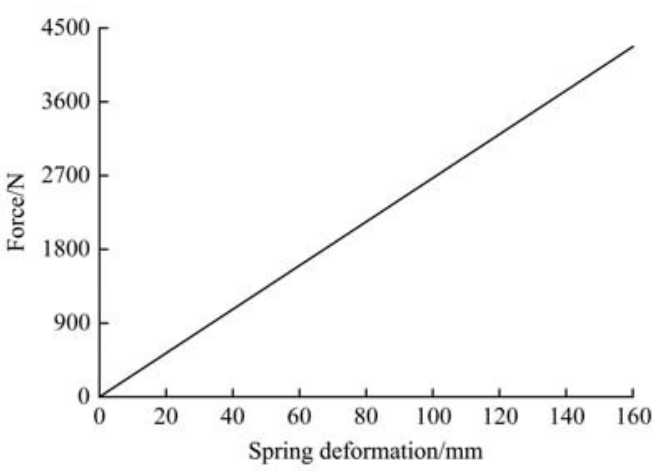

b. Spring stiffness test

Figure 2 Test of suspension parameters

Table 1 Parameters of suspension

\begin{tabular}{|c|c|}
\hline Parameter & Value \\
\hline Pendulum rod length $l / \mathrm{m}$ & 1.1 \\
\hline $\begin{array}{l}\text { Damping coefficient of lateral stabilizer shock absorber } C_{1} \\
/ \mathrm{N} \cdot \mathrm{s} \cdot \mathrm{m}^{-1}\end{array}$ & 11389.7 \\
\hline Damping coefficient of vertical shock absorber $C_{2} / \mathrm{N} \cdot \mathrm{s} \cdot \mathrm{m}^{-1}$ & 5110 \\
\hline $\begin{array}{l}\text { Spring stiffness coefficient of lateral stabilizer shock absorber } K_{1} \\
/ \mathrm{N} \cdot \mathrm{m}^{-1}\end{array}$ & 25760 \\
\hline spring stiffness coefficient of Vertical shock absorber $K_{2} / \mathrm{N} \cdot \mathrm{m}^{-1}$ & 13350 \\
\hline Mass of the spray boom $/ \mathrm{kg}$ & 922.6 \\
\hline Moment of inertia around the center of mass $I_{2} / \mathrm{kg} \cdot \mathrm{m}^{2}$ & 32700 \\
\hline
\end{tabular}

\subsection{Rigid-flexible coupling model}

The spray boom is usually space truss structure with large flexibility and weak damping. During the process of pesticide application in the field, it may be subjected to external incentives from the spray vehicle rolling, water tank sloshing and engine vibration and easy to stimulate low order modes of deformation of the spray boom. Besides, when the natural frequency of boom is consistent with the natural frequency of the pendulum suspension, resonating create the enormous destruction ${ }^{[19]}$, so spray boom should be treated as a flexible body in the multi-body dynamics modeling process.

The geometric model of the spray boom is imported into the finite element software ABAQUS, then defining the material parameters that the density is $7.85 \times 10^{-6} \mathrm{~kg} / \mathrm{mm}^{3}$, elastic modulus is $2.1 \times 10^{5} \mathrm{MPa}$, Poisson ratio is 0.3 . The model was meshed by using hexahedral element C3D8R, welding was simulated by using binding constraints. Reference points were established at the connecting position of the spray rod and the suspension hinge, then coupled reference points with the constrained parts of boom. Constraints were added on the reference points, the first 15 orders natural frequency and mode shapes were calculated by using the Lanczos method (Figure 3). After modal analysis, import modal neutral file (MNF) to ADMS software through the ADAMS/Flex interface, then we established a dynamic model of pendulum boom suspension and the inertial coordinate system $O X Y Z$ is shown in Figure 4.
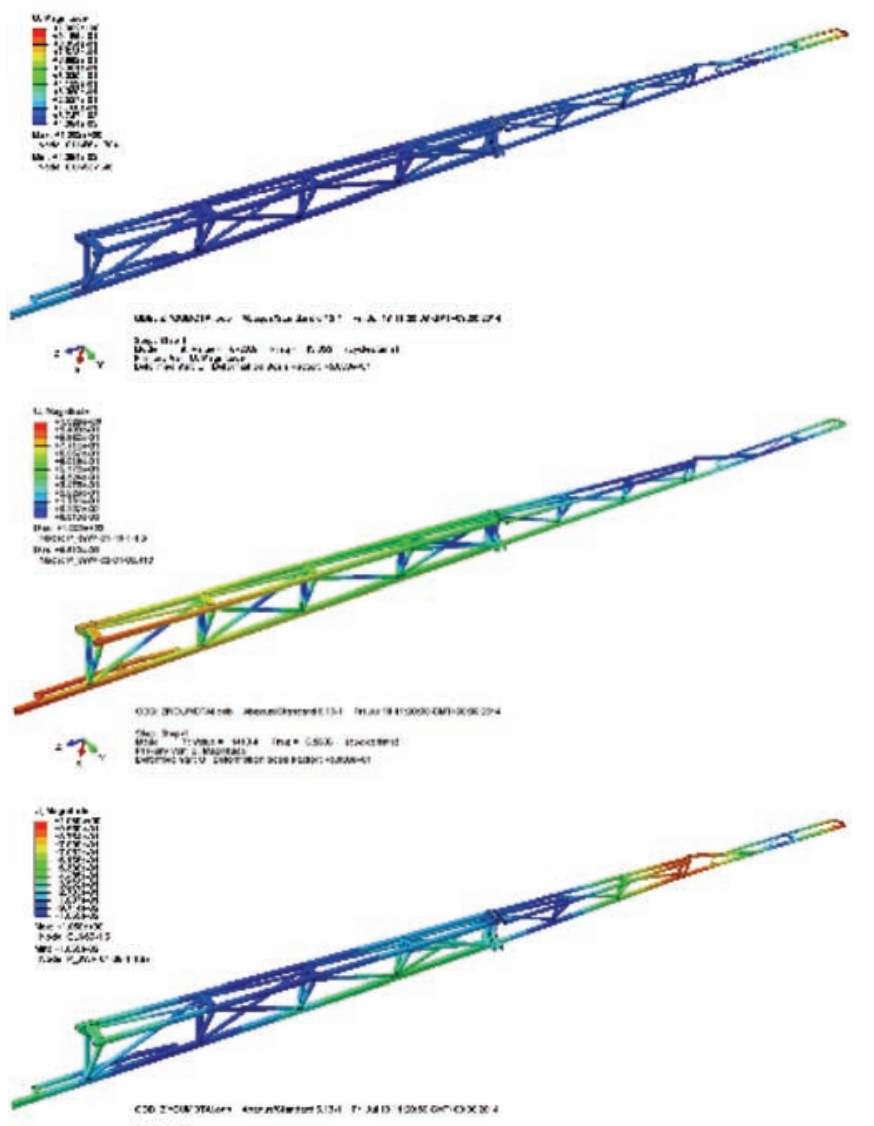

: 47. .

Figure 3 Modal shapes of one side boom

This paper mainly studies boom rolling motion (rotation around the $X$ axis) and jolting (along the pendulum rod 2). In ADAMS software, the pendulum rod was connected to the support frame by a revolute joint, the center frame was connected to the pendulum rod by a translation joint, the center frame was 
connected to the bracket by a flexible connection that consisting of spring and damping. Another flexible connection was added between the center frame and the support frame. Sprayer vehicle was represented by a mass point, so we can simulate the movements of the vehicle by applying motions on the mass point, the movements of support frame were coupled with the motion of the mass point. As shown in Figure 4 the rigid-flexible coupling model of boom suspension was built.

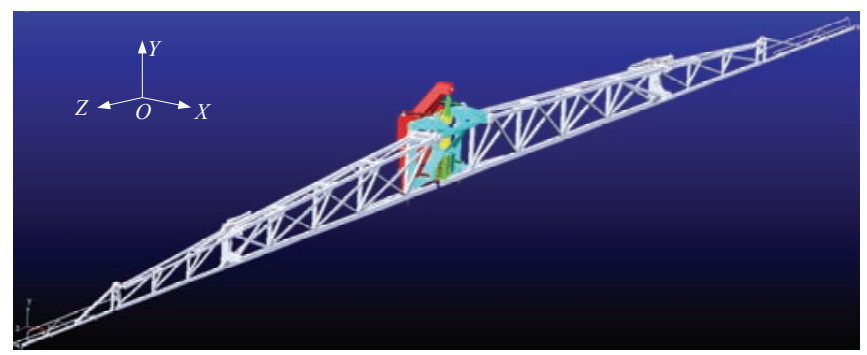

Figure 4 Rigid-flexible coupling model of boom and suspension

\subsection{Model validation}

As is shown in Figure 5, a 28 meters long boom that consists of 5 sections is constructed from a 3-dimensional design offering exceptional strength, stability and low maintenance, folding and unfolding driven by hydraulic systems, equipped with tank capacity $4500 \mathrm{~L}$, the sprayer vehicle is fitted with a four stroke engine with power of $182 \mathrm{~kW}$. The suspension was fixed on the Stewart motion simulator 3 with six degrees of freedom by installing a fixture. The Stewart six DOF motion simulator can reproduce the boom movements that disturbed by a self-propelled agricultural vehicle or a trailed or mounted tractor, enabling field conditions to be simulated in the laboratory. The motion simulator built at Nanjing research institute for agricultural mechanization (NRIAM) of national ministry of agriculture.

Boom rolling (around $X$ axis) and center vibration (along the pendulum rod 2) are obtained with the following system: An inertial measurement sensor (Ellipse-D-G4A2B1, SBG System) is mounted at the center of the boom below the rotation point $O$, it is able to measure the roll angle of the boom with respect to the laboratory ground. The vibration displacement along the pendulum $\operatorname{rod} P Q$ is measured by a linear variable differential transformer (LVDT) (SDVG20-250, Soway); test data are sampled by using a wireless dynamic signal acquisition and analysis system (DH5902, DONGHUA TEST).

To ensure the quality of the simulation model and thus the quality of the optimization, the model should be validated. Anthonis ${ }^{[3]}$ applied a step excitation to the suspension, and measure of the motion of the boom, then verified the accuracy of the suspension model. In this study, it was performed by an experiment in which the boom was tilted $5.7^{\circ}$ and released by using a cable to pull one side of the boom, and boom rotation was measured by the inertial measurement sensor. In the simulation, the boom is released from the same angle and both time signals are compared (Figure 6a). The root mean square error (RMSE) between the simulation and experimental angle is $0.0146^{\circ}$. Utilizing the same approach, the boom was raised $50 \mathrm{~mm}$ and released by a bridge crane in the laboratory, recorded boom center motion displacement signals with time, and simulation and test result are compared in Figure 6b, the root mean square error (RMSE) between the simulation and experimental displacement is $1.3164 \mathrm{~mm}$. Good correspondence is noted between the simulation and test, which verifies the correctness of the rigid-flexible coupling model of suspension-boom system and can be used for the optimization of the boom suspension system.

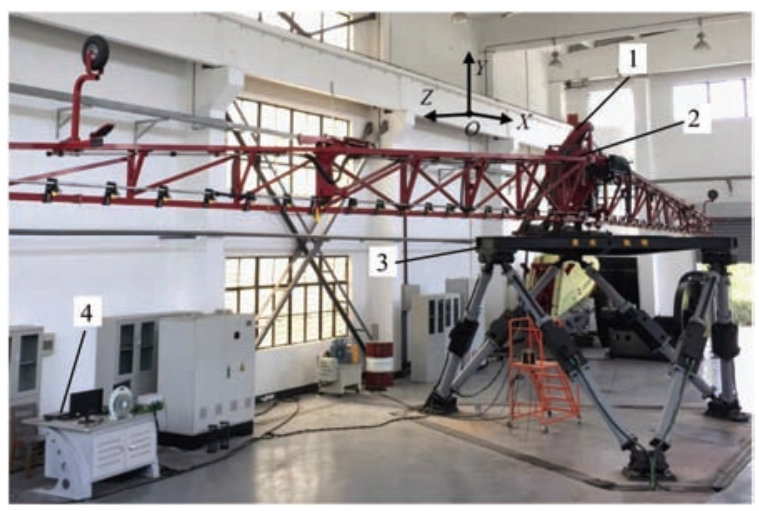

a. Generic view of test bench

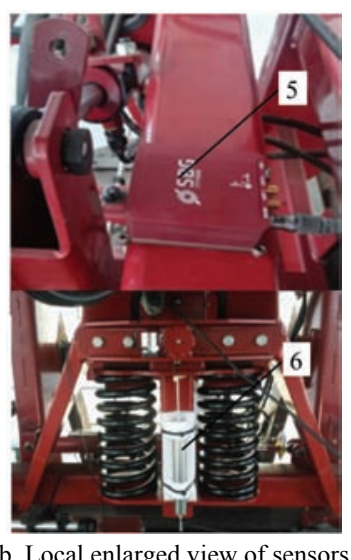

1. Spray boom and pendulum suspension system 2. Sensors and test system 3. Stewart six DOF motion simulator 4. Console 5. Inertial measurement sensor 6. LVDT displacement sensor

Figure 5 Motion Simulator for spray boom suspension

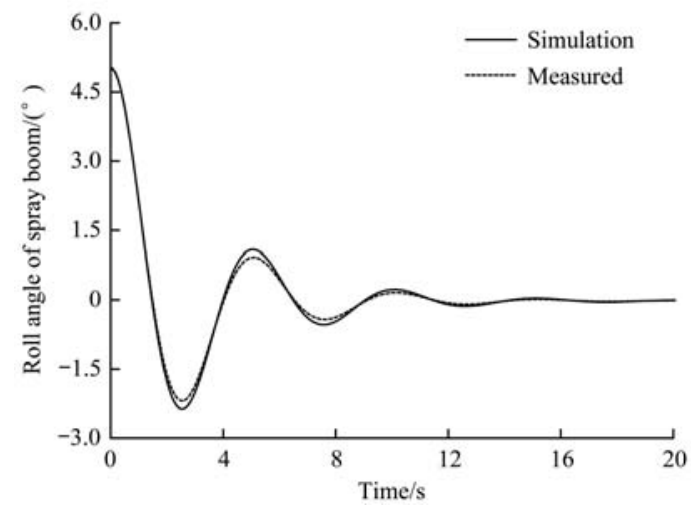

a. A step excitation of $5.7^{\circ}$ roll input

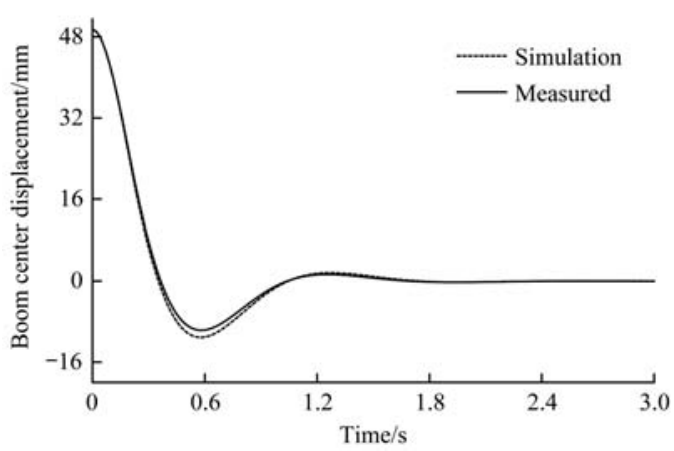

b. A step excitation of $50 \mathrm{~mm}$ transversal input

Figure 6 Presentation of the motion of the boom when applying a step excitation 


\section{Experimental design and RBFNN modelling}

\subsection{Design variables and objective functions}

Spring stiffness $K_{1}$ and damping coefficient $C_{1}$ of the vertical shock absorbers, spring stiffness $K_{2}$ and damping coefficient $C_{2}$ of the lateral shock absorber have an important influence on the dynamic characteristics of pendulum suspension and stability of spray boom. Therefore, the scaling factors $X_{1}, X_{2}, X_{3}, X_{4}$ of parameters $C_{1}, C_{2}, K_{1}, K_{2}$ were chosen as the design variable, and the design variables were $\chi=\left\{X_{1}, X_{2}, X_{3}, X_{4}\right\}$, which is shown in Table 2, RMS of the boom roll angle and RMS of the boom center vibration displacement were defined as the objective functions $Y_{1}$, $Y_{2}$ respectively.

Table 2 Value range of design variable

\begin{tabular}{lccc}
\hline \multicolumn{1}{c}{ Design variables } & $\begin{array}{c}\text { Initial } \\
\text { value }\end{array}$ & $\begin{array}{c}\text { Lower limit } \\
\text { value }\end{array}$ & $\begin{array}{c}\text { Upper limit } \\
\text { value }\end{array}$ \\
\hline Scaling factor of damping coefficient $C_{1} / X_{1}$ & 1 & 0.7 & 1.3 \\
Scaling factor damping coefficient $C_{2} / X_{2}$ & 1 & 0.7 & 1.3 \\
Scaling factor of spring stiffness $K_{1} / X_{3}$ & 1 & 0.7 & 1.3 \\
Scaling factor of spring stiffness $K_{2} / X_{4}$ & 1 & 0.7 & 1.3 \\
\hline
\end{tabular}

\subsection{Dynamic condition applied to simulation and optimization}

When travelling on a field the sprayer vehicle is excited to do random movements that are transmitted to the boom. So the movements of sprayer vehicle are essential input excitation to study the dynamic behavior of a boom suspension, during pesticide application in the field, the main excitations that affecting the stability of the spray boom are the rolling motion and vertical translation of the spray vehicle, the two kinds of movement were selected to represent typical excitations for the sprayer movements.

Next, a simplified simulation model of self-propelled sprayer with pendulum suspension is developed in ADAMS software (Figure 7). Simulations are done for the sprayer that traverses a standardized track, comparable to a freshly ploughed field, at a constant speed of $7 \mathrm{~km} / \mathrm{h}$. The soil irregularities profiles are compiled according to the ISO 5008 norm $^{[4,20]}$. Figure 8 shows a part of the soil function from the norm. All parameters of the vehicle such as tire type and chassis parameters were supplied by the manufacturer. The weight, moment of inertia, and locations of the center of gravity were determined from a virtual prototype designed in SolidWorks.

During simulations, the translations and rotations at the mounting point of the boom suspension were calculated, as shown in the Figure 9. These disturbances will be applied as input excitations to simulate boom movements with pendulum suspension (as shown in the Figure 9). Hence the time of simulation and experiment will be greatly shorten.

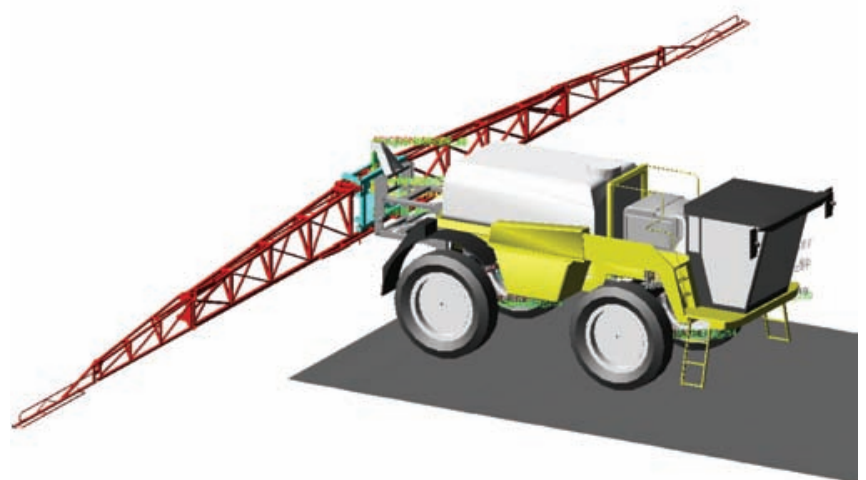

Figure 7 A model of self-propelled sprayer with pendulum boom suspension

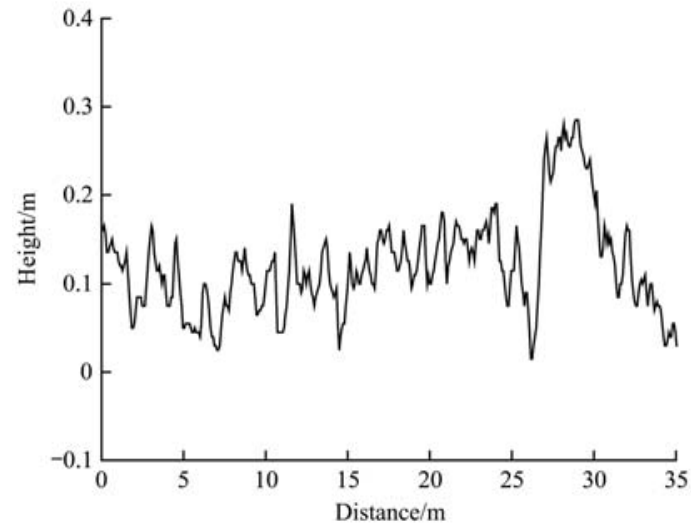

Figure 8 A part of soil profile below tires

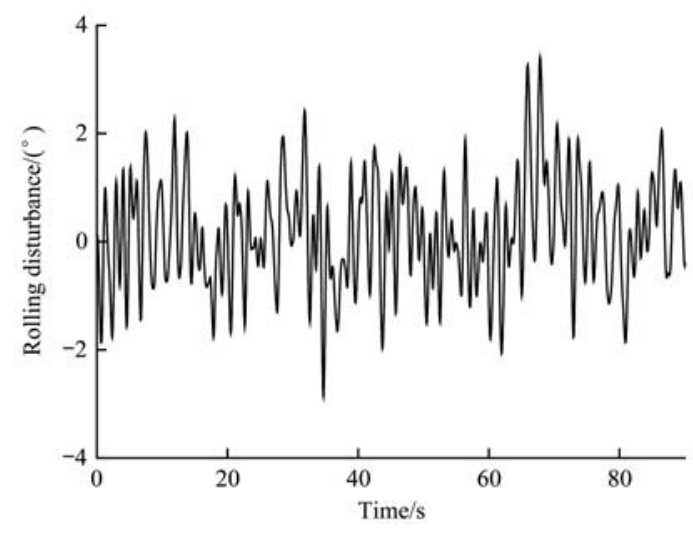

a. Rolling disturbance at the mounting point

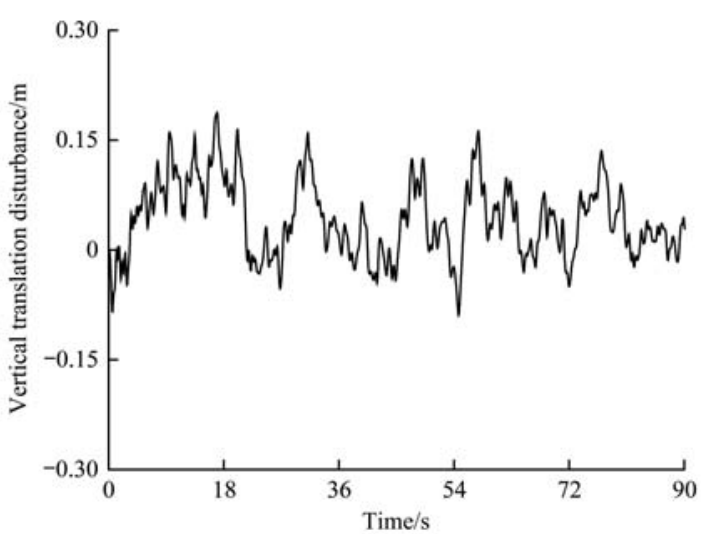

b. Vertical translation disturbance at the mounting point

Figure 9 Disturbance caused by spray vehicle motion

\subsection{Optimal Latin hypercube design}

The sample space provided by experimental design is the basis of constructing approximate model, when the approximation model is established. The accuracy of the approximate model can be greatly improved by choosing the reasonable sampling points.

The optimal Latin hypercube design (Opt LHD) technique is a modified Latin hypercube design (LHD) where the combination of factor levels for each factor is optimized, rather than randomly combined. The Opt LHD minimize the integrated mean squared error and maximize the entropy ${ }^{[19]}$. The Opt LHD sampling improves the LHD in aspect of uniformity and stability. It can make the fitting between factors and responses more accurate. With the help of the optimal Latin hypercube design of experiment method $^{[22]}$, the effects of factors $X_{1}, X_{2}, X_{1}, X_{2}$ on the dynamic behavior of sprayer booms will be investigated, 128 samples were obtained by the optimal Latin hypercube sampling, and the map of the sampling was given in Figure 10. Based on the samples, 128 sets of dynamics simulation for pendulum boom suspension 
were carried out in ADAMS software and 128 sets of responses $\left(Y_{1}, Y_{2}\right)$ were obtained.

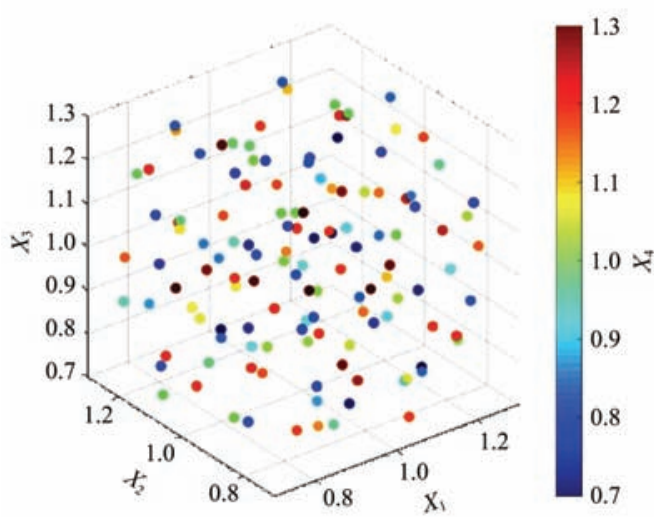

Figure 10 Map of the Opt LHD sampling

The main effect analysis diagrams was shown in the Figure 11, The influence of $X_{1}, X_{3}$ on the roll angle of the spray boom is significant, with the increase of $X_{1}, X_{3}$ the efficiency shows an upward trend, as shown in the Figure 11a. The influence of factor $X_{4}$ on the vertical displacement of the boom center is significant, with the increase of $X_{4}$, the object $Y_{2}$ decreases firstly and then increases, in the given design range, $X_{4}$ has an optimal value, the change of $X_{1}, X_{2}, X_{3}$ had little effect on object $Y_{2}$.

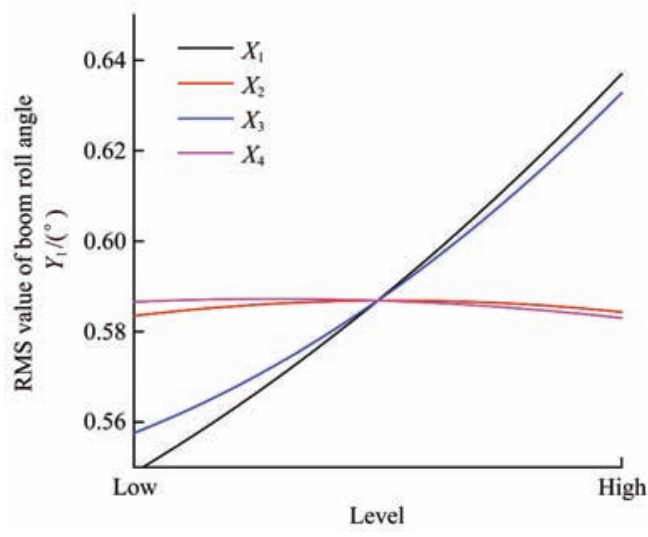

a. Main effects plot for $Y$

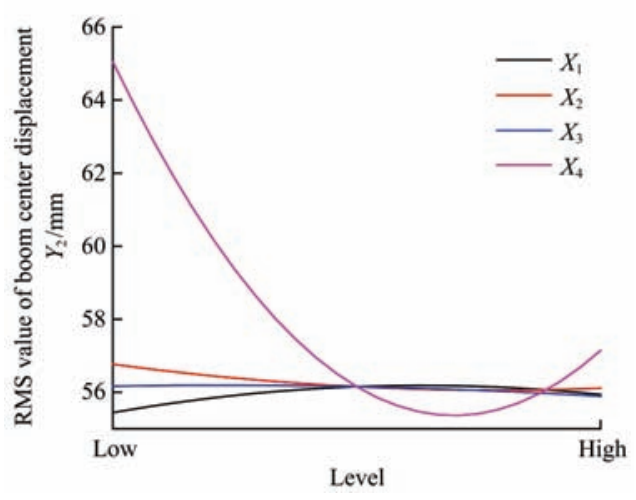

b. Main effects plot for $Y_{2}$

Figure 11 Main factor effect analysis of factors on object

The analysis diagram of the influence of $X_{1}, X_{2}, X_{3}$, and $X_{4}$ on $Y_{1}, Y_{2}$ in the design space is shown in pareto plots (Figure 12). The bars in the graph represent the percentage of each variable affecting the objects. Red bars mean negative effect, blue bars means positive effect. Which factors have a great impact on the objects can be seen clearly. The effcet of factor $X_{1}, X_{3}$ on the roll angle of the spray boom is significant, factor $X_{4}$ has a greater negative impact on target $Y_{2}$.

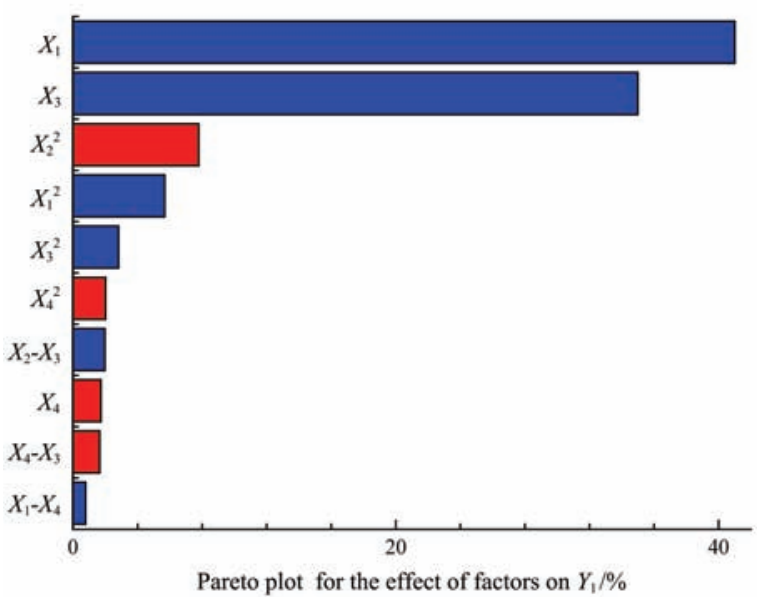

a. Pareto plot for the effect of factors on object $Y_{1}$

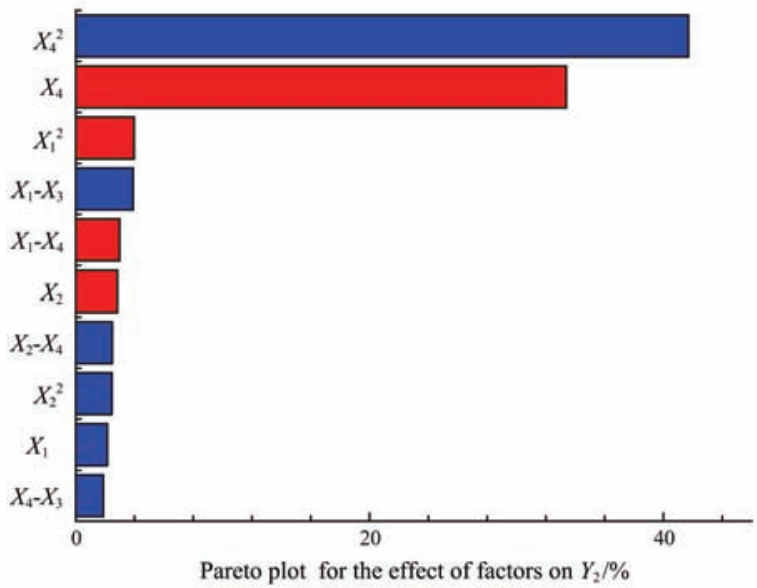

b. Pareto plot for the effect of factors on object $Y_{2}$

Figure 12 Pareto plot for the effect of factors on object

4.4 Approximation model for predicting objective functions

There are three commonly used approximation algorithms: response surface model, kriging model, and radial basis function neural network model ${ }^{[23]}$. As mentioned before, the scaling factor $X_{1}, X_{2}, X_{3}, X_{4}$ of parameters $C_{1}, C_{2}, K_{1}, K_{2}$ are chosen as the design variable, RMS of the boom roll angle and RMS of the boom center vibration displacement are used as the objective functions $Y_{1}, Y_{2}$ respectively.

Based on the samples, the predicted boom rolling angle and jolting displacement using the RBFNN, the kriging method, and the response surface model respectively, and the fitting precision were shown in Table 3. It can be seen that most of the RBFNN predicted values agree with the simulation results better than the other two methods, the RBFNN model has a best fitting precision and higher fitting efficiency and fitting reliability of both objectives are greater than 0.90 , while the approximate model credibility based on the remaining methods have only one objective greater than 0.9. In respect of fitting efficiency, kriging model takes longer, while the polynomial response surface model and RBF model are fitted with high efficiency, which is mainly because that the maximum value of the kriging function is obtained by optimal solution of multi-dimensional and multi-modal function and it is time consuming. Thus, it is appropriate to conduct the following analysis and optimization based on the RBFNN prediction system.

To test the accuracy of the RBFNN prediction system, ten samples not included in the prediction were used in the testing. The test results (shown in Figure 13) show a good agreement between the predicted value and the numerical experiments, the 
predicted value and the simulation value are near the slash. So, it is reasonable to use the proposed RBFNN prediction system instead of multi-body dynamics simulations to save computational cost, and the RBF neural network function is suitable for optimization of the dynamic parameters of the suspension system.

Table 3 Accuracy comparison of three approximations

\begin{tabular}{ccccc}
\hline $\begin{array}{c}\text { Approximation } \\
\text { algorithms }\end{array}$ & Objectives & $\begin{array}{c}\text { Maximum } \\
\text { error }\end{array}$ & $\begin{array}{c}\text { Root mean } \\
\text { square error }\end{array}$ & $R^{2}$ \\
\hline $\begin{array}{c}\text { Three order response } \\
\text { surface model }\end{array}$ & $Y_{1}$ & 0.0988 & 0.09341 & 0.91996 \\
\hline Kriging model & $Y_{2}$ & 0.13328 & 0.11044 & 0.86149 \\
\hline \multirow{2}{*}{ RBFNN model } & $Y_{1}$ & 0.09127 & 0.10177 & 0.90978 \\
& $Y_{2}$ & 0.10647 & 0.1079 & 0.89635 \\
\hline & $Y_{1}$ & 0.04096 & 0.06373 & 0.96554 \\
\hline
\end{tabular}
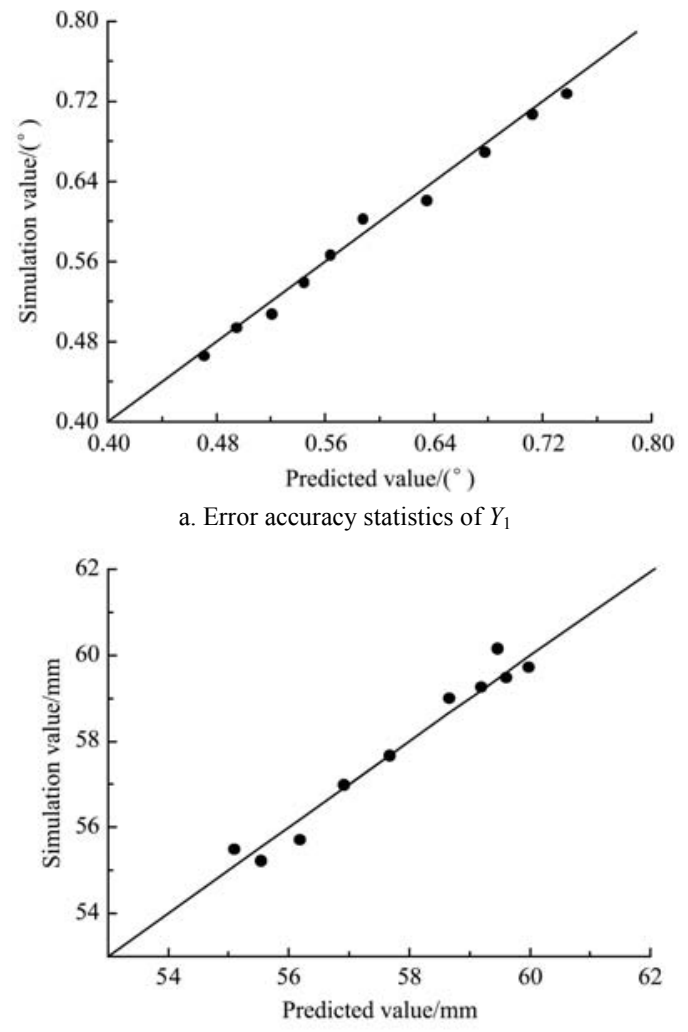

b. Error accuracy statistics of $Y_{2}$

Figure 13 Objectives prediction error accuracy statistics of approximation model

\section{Optimization of suspension system parameters based on NSGA-II}

\subsection{The optimization algorithm of NSGA- II}

The non-dominated sorting genetic algorithm (NSGA-II) was proposed by K. Deb and S. Agrawal ${ }^{[24,25]}$. It is an improved version of NSGA. It is one of the main methods for the multi-objective genetic algorithm. NSGA-II with a low computational complexity, effective elite strategy and the unnecessity to specify the sharing radius, has become one of the main methods for the multi-objective genetic algorithm and has been successfully applied to solve a variety of complex engineering optimization problems ${ }^{[26]}$. In view of this, the NSGA-II algorithm is chosen to optimize the parameters of the boom suspension.

The optimization parameters of NSGA- II are set as follows: population size $N=20$, maximal iteration number $g_{\max }=100$, crossover probability is 0.85 and mutation probability is 0.01 , and the probability of variation of the total number of layers in the repeated duplicated individuals and the denser individuals are both 0.001 .

\subsection{The multi-objective optimization based on NSGA- II}

The multi-objective optimization problem in this study was defined as follows:

$$
\left\{\begin{array}{rr}
\operatorname{minimize} Y_{1}= & f_{1}\left(X_{1}, X_{2}, X_{3}, X_{4}\right) \\
\operatorname{minimize} Y_{2}= & f_{2}\left(X_{1}, X_{2}, X_{3}, X_{4}\right) \\
& X_{1} \in(0.7,1.3) \\
\text { Subject to: } \quad & X_{2} \in(0.7,1.3) \\
& X_{3} \in(0.7,1.3) \\
& X_{4} \in(0.7,1.3)
\end{array}\right.
$$

The flowchart of the proposed optimization method based on the Opt LHD, the RBFNN Approximation model, and the multi-objective optimization based on NSGA- II was given as below (Figure 14). The simulation of rigid-flexible coupling dynamic model was integrated into the multidisciplinary optimization analysis platform Isight, the objective functions were calculated by using the Matlab software, then a multi-objective optimization model for spray boom suspension dynamic behavior was established.

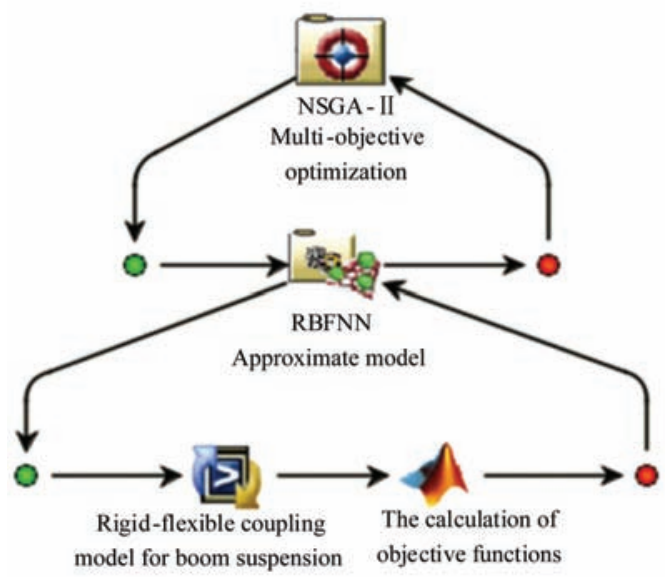

Figure 14 Optimization model

\subsection{Results analysis and experimental verification on stewart} motion simulator

The pareto frontier were achieved by the NSGA- II, different combinations of optimal tradeoff solutions can be selected from these solutions. Weighted method is one of the representative algorithms of multi-objective normalization algorithm ${ }^{[27]}$, import a direction $\boldsymbol{w}=\left(w_{1}, w_{1}\right)$ determined by the weight coefficient to the target space $\left(f_{1}, f_{1}\right)$, the corresponding contour is imported in the target space, the tangent point of this contour and feasible design space is an optimum solution.

Because boom rolling movement has a great influence on the uniformity of spray, defining weight coefficients $w_{1}=0.7, w_{2}=0.3$ during the optimization process. The optimized results are shown in the Table 4, the damping values of shock absorbers ware adjusted by adjusting the opening of the damping hole according to the optimization result, on the other hand, the springs of suspension is redesigned and customized.

After adjusting the suspension parameters, we carried out the dynamic test of suspension in Stewart motion simulator with six degrees of freedom (show as Figure 5), and the excitation of the mounting position of the suspension(show as Figure 9) in the 3.3 section was reproduced on the motion simulator, the roll angle and jolting displacement curve of the spray boom were measured by the 
sensors, as shown in the solid line in the Figure 15, at the same time, test results were listed in the Table 4. The RMS of a spray boom roll angle is $0.6001^{\circ}$, the error rate of model optimization result relative to experimental value is $2.25 \%$. The RMS of vertical vibration displacement is $61.83 \mathrm{~mm}$, the error rate of model optimization result relative to experimental value is $8.74 \%$. The experiment proved that the RMS of the boom roll angle was reduced by $14.76 \%$ and the RMS of the boom center displacement was reduced by $12.43 \%$ compared with the original suspension system. The optimization results show that this optimization method improves the dynamic characteristics of the suspension and the stability of spray boom.

\section{Table 4 Comparison of optimization results with experiment data}

\begin{tabular}{|c|c|c|c|c|c|c|}
\hline & $\begin{array}{l}\text { Damping coefficient } \\
\qquad C_{1} / \mathrm{N} \cdot \mathrm{s} \cdot \mathrm{m}^{-1}\end{array}$ & $\begin{array}{l}\text { Damping coefficient } \\
\qquad C_{2} / \mathrm{N} \cdot \mathrm{s} \cdot \mathrm{m}^{-1}\end{array}$ & $\begin{array}{c}\text { Spring stiffness } \\
K_{1} / \mathrm{N} \cdot \mathrm{m}^{-1}\end{array}$ & $\begin{array}{l}\text { Spring stiffness } \\
K_{2} / \mathrm{N} \cdot \mathrm{m}^{-1}\end{array}$ & $\begin{array}{c}\text { RMS of the boom roll } \\
\text { angle } Y_{1} /\left(^{\circ}\right)\end{array}$ & $\begin{array}{c}\text { RMS of the boom center } \\
\text { displacement } Y_{2} / \mathrm{mm}\end{array}$ \\
\hline Initial value & 11.39 & 5.11 & 25.76 & 13.35 & 0.704 & 70.609 \\
\hline Optimum solution & 14.069 & 5.882 & 21.167 & 10.306 & 0.5866 & 56.428 \\
\hline Experimental value & 14.1 & 5.9 & 21.2 & 10.3 & 0.6001 & 61.831 \\
\hline
\end{tabular}

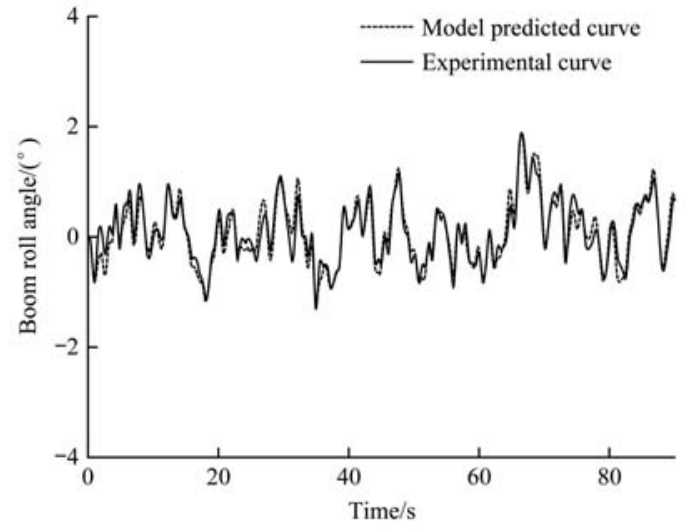

a. Roll angle of spray boom

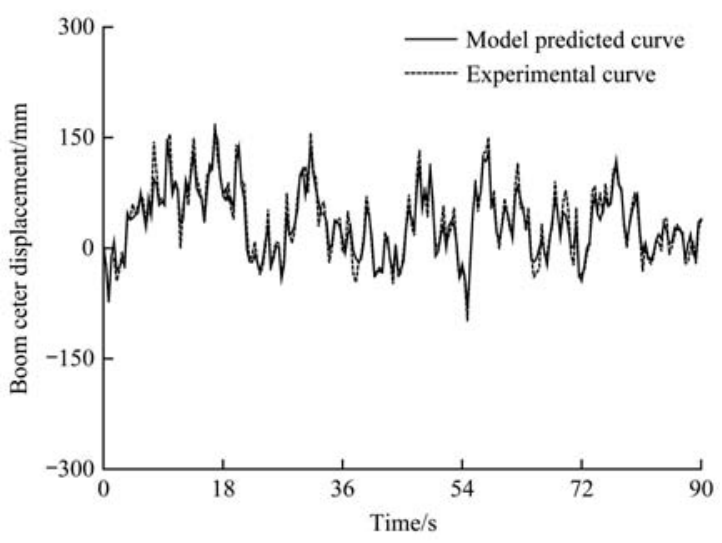

b. Vibration displacement of boom center

Figure 15 Comparison between predicted and experiment

In order to test the spray performance after suspension optimization, a test bench was built the spray performance test bench for spray boom, show as Figure 16, the initial spraying height of $0.6 \mathrm{~m}$ from test plane in combination with a fixed flat fan nozzle (F110-02, PRESS $0.2 \mathrm{MPa}$ ) with top angle of $110^{\circ}$ spacing of $0.5 \mathrm{~m}$.

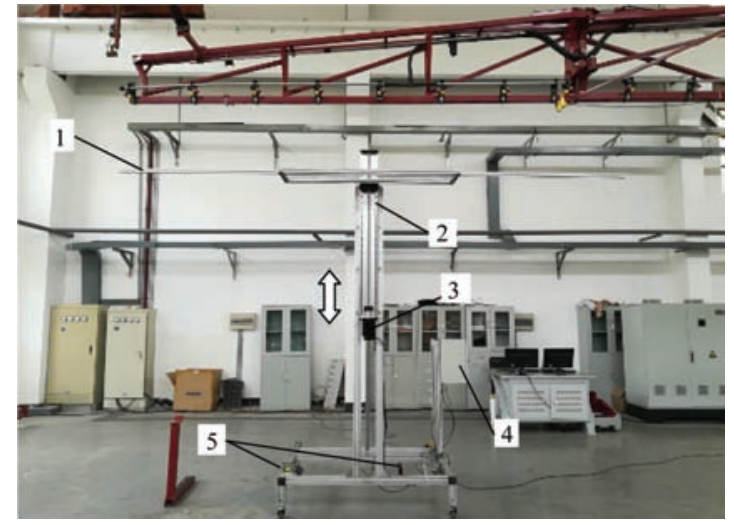

1. Beam for pasting WSP 2. Lifting platform 3. Stepper motor 4. Control cabinet 5. Laser range sensors

Figure 16 Test bench for spray deposit distribution of the spray boom

Then we tested the spray deposit distribution of the spray boom in dynamic conditions based on the Stewart motion simulator. At the beginning of the experiment, the movements of the spray boom are simulated by a Stewart motion simulator, and the dynamic spray deposit distribution below the moving boom is measured using a special movable test bench in well-defined conditions. Spray deposits are collected with water-sensitive papers (WSP). WSP were stapled flat, face-up on top of beam mounted on the test bench in a row parallel to the boom. The movable test bench passes through bottom of the spray boom, the moving velocity of the test bench was recorded by laser range sensors (LTF12UC2LDQ, Banner), and the moving speed was about $1.5 \mathrm{~m} / \mathrm{s}( \pm 0.2 \mathrm{~m} / \mathrm{s})$. After the test, sprayed WSP were stored in individually labeled envelopes and processed in the laboratory by an image analysis system using image pixels methods. Comparison of WSP sampler results included percent coverage and droplet density (before and after optimization of suspension) show in Table 5. Five groups of tests were carried out in dynamic condition base on the motion simulator, compared with the boom suspension that before optimization, the coefficient of variation (CV) of five replicate tests runs for spray coverage and droplet density ware calculated, both of them decreased in different degrees. Spray coverage and droplet density ranged from $15.82 \%$ to $23.31 \%$ and from 139.4 to 184.6 spots $/ \mathrm{cm}^{2}$, respectively. It also can be seen that $\mathrm{CV}$ of spray deposit distribution at the boom tip was relatively larger. In addition, before suspension optimization, CV of spray coverage along the transverse of boom is $24.8 \%$, and the coefficient of variation is $14.68 \%$ for the optimized boom.

In order to get realistic drive signals for the platform, field trails had been conducted to measure movements of a self-propelled sprayers. When the sprayer applying pesticide in wheat field at Hongze Lake Farm in Jiangsu Province, April 2017, the movements of the spray vehicle were measured as time-domain signal by using the inertial measure unit (Ellipse-D, SBG), due to space limitations, only one figure that describe rolling motion of a vehicle was given,(show as Figure 17a). The measured signal is processed by removing trend item and low-pass filtering, then the motion simulator is used to reproduce the movements that disturb 
the spray boom in the laboratory, enabling field conditions to be simulated. The measured RMS of the rolling angle of the boom is $0.6290^{\circ}$, the root mean square error (RMSE) of the experimental results and simulation results is $0.2501^{\circ}$. The measured RMS of the vibration displacement of the boom is $62.279 \mathrm{~mm}$, the RMSE of the experimental results and simulation results is $8.457 \mathrm{~mm}$.

Table 5 Comparison of spray distribution at boom tip before and after optimization of suspension

\begin{tabular}{|c|c|c|c|c|c|c|c|}
\hline \multirow{2}{*}{$\begin{array}{l}\text { Spray deposit } \\
\text { distribution }\end{array}$} & & \multicolumn{3}{|c|}{ Left Boom } & \multicolumn{3}{|c|}{ Right boom } \\
\hline & & $9 \mathrm{~m}^{[\mathrm{a}]}$ & $10.5 \mathrm{~m}$ & $12 \mathrm{~m}$ & $9 \mathrm{~m}$ & $10.5 \mathrm{~m}$ & $12 \mathrm{~m}$ \\
\hline \multirow{4}{*}{$\begin{array}{l}\text { Original boom } \\
\text { suspension }\end{array}$} & \multirow{2}{*}{ Spray coverage $/ \%$} & 17.21 & 14.23 & 13.21 & 17.34 & 21.21 & 25.15 \\
\hline & & $(19.46)^{[b]}$ & (34.14) & (47.73) & (21.14) & (39.68) & $(46.45)$ \\
\hline & \multirow{2}{*}{$\begin{array}{l}\text { Droplet density } \\
\text { /spots } \cdot \mathrm{cm}^{-2}\end{array}$} & 159.10 & 128.16 & 110.4 & 133.00 & 151.10 & 158.90 \\
\hline & & $(22.63)$ & (24.09) & $(51.43)$ & $(22.63)$ & (33.55) & (41.65) \\
\hline \multirow{4}{*}{$\begin{array}{l}\text { Optimized boom } \\
\text { suspension }\end{array}$} & \multirow{2}{*}{ Spray coverage $/ \%$} & 15.82 & 18.34 & 17.45 & 16.50 & 19.73 & 23.31 \\
\hline & & (13.98) & $(24.37)$ & $(20.76)$ & (12.13) & (19.62) & $(20.28)$ \\
\hline & \multirow{2}{*}{$\begin{array}{l}\text { Droplet density } \\
/ \text { spots } \cdot \mathrm{cm}^{-2}\end{array}$} & 139.40 & 168.50 & 159.20 & 184.60 & 154.20 & 179.7 \\
\hline & & $(10.97)$ & (12.24) & $(18.30)$ & $(10.76)$ & $(20.71)$ & (18.87) \\
\hline
\end{tabular}

Note: [a] The transverse distance measured from the center of the boom. [b] CV of five replicate test runs.

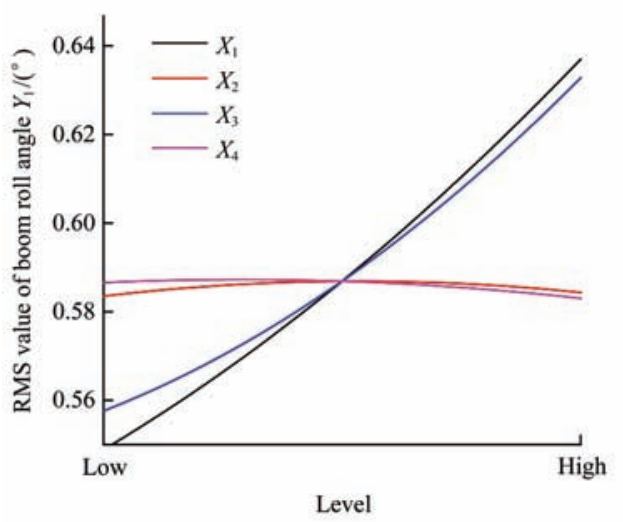

a. Rolling motion of sprayer vehicle

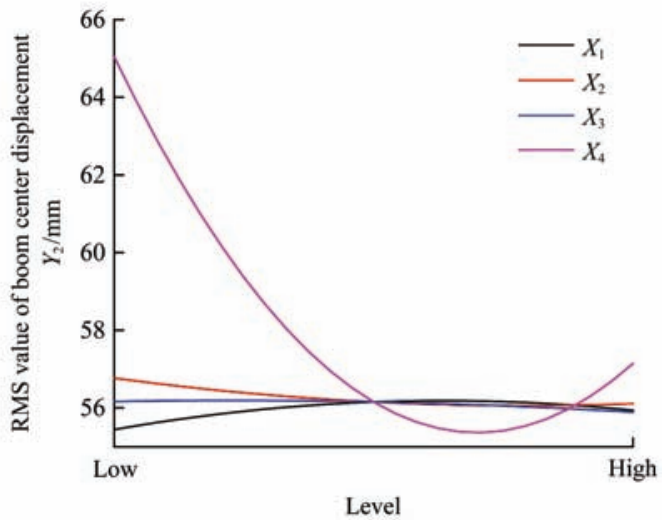

b. Comparison of boom rolling motion between predicted and experiment

Figure 17 Reproduce movements of the sprayer vehicle in the laboratory conditions

\section{Conclusions}

A pendulum vertical suspension for a $28 \mathrm{~m}$ boom of the crop sprayer has been optimized, based on a flexible-rigid coupling dynamics model of the boom suspension. Considering boom movements in vertical plane dramatically affect the spray distribution pattern, using RMS of the boom roll angle and RMS of the boom center vibration displacement as the objective functions, the stiffness and damping of the suspension systems as design variables. An RBFNN-based predicting system was then founded and trained based on the Opt LHD sampling and validated by comparing to the kriging method and response surface method. A multi-objective optimization was carried out based on the NSGAII method. After that, a correction of Suspension parameters were conducted to validity of the optimal results, and Stewart motion simulator was used to simulate the travel of a sprayer on the field. Main conclusions can be drawn as follows:

1) Modal analysis of the boom was carried out by using ABAQUS software, then the dynamic rigid coupling model of the virtual prototype of the spray boom suspension system was established in ADAMS. Step response experiment on the test bench was carried out and the accuracy of the suspension model was verified, RMSE between the simulation and experimental for boom roll motion was $0.0146^{\circ}$, RMSE between the simulation and experimental for boom center vibration displacement was $1.3164 \mathrm{~mm}$.

2) The proposed multi-objective optimization method based on the Opt LHD, the RBFNN, and the NSGA-II can predict the responses (roll angle and vibration displacement of the boom) and reduce the responses precisely and efficiently. Thought defining weight coefficients, an optimal solution is obtained. Then adjusting the suspension parameters, reproduce the movements that used for suspension parameter optimization in the laboratory, the RMS of the boom roll angle and boom center vibration displacement are $0.6001^{\circ}$ and $61.83 \mathrm{~mm}$, the experiment proved that the RMS of the boom roll angle and the boom center displacement for optimized solution were reduced by $14.76 \%$ and $12.43 \%$ compared with the original suspension system, the stability of the spray boom has been significantly improved, and the uniformity of spray distribution has also improved.

3) When the sprayer applying pesticide in wheat field at Hongze Lake Farm in Jiangsu Province, the movements of the spray vehicle were measured, reproducing the movements on the Stewart motion simulator, the motion of the boom (rolling and jolting) was obtained in the laboratory. The tested standard deviation of the rolling angle and vibration displacement of the boom are $0.6290^{\circ}$ and $62.279 \mathrm{~mm}$.

4) Next steps, in order to obtain more realistic drive signals for the motion simulator, field experiments will be conducted to measure movements of a number of self-propelled, trailed and tractor mounted sprayers, then a collection of drive signals resulting from these tests would be selected to represent typical excitations for the experiment of boom suspension, and a big number of field situations would also be taken into the suspension 
optimization. Furthermore, we will use laser particle size analyzer, PIV and high-speed camera to investigate the effects of suspension, boom movements on VMD, NMD, and other property of droplets.

\section{Acknowledgements}

This study was financially supported by the National Key Research and Development Program of China (2016YFD0200705), the National Natural Science Foundation of China (Grant No. 51605236), the Independent Innovation Fund of Agricultural Science and Technology of Jiangsu Province (CX (16) 1043). The financial support from the above funds and organizations are gratefully acknowledged. Also thanks to all the postgraduate students working in the Crop Protection and Environment Engineering Technology Centre (CPEET), who provided their input to this study.

\section{[References]}

[1] Deprez K, Anthonis J, Ramon H, Hvan B. Development of a slow active suspension for stabilizing the roll of spray booms, Part 1: Hybrid modelling. Biosystems Engineering, 2002; 81(2): 185-191.

[2] Deprez K, Anthonis J, Ramon H. System for vertical boom corrections on hilly fields. Journal of Sound \& Vibration, 2003; 266(3): 613-624.

[3] Anthonis J, Audenaert J, Ramon H. Design optimization for the vertical suspension of a crop sprayer boom. Biosystems Engineering, 2005; 90(2): 153-160.

[4] Kennes P, Ramon H, Baerdemaeker J D. Modelling the effect of passive vertical suspensions on the dynamic behavior of sprayer booms. Journal of Agricultural Engineering Research, 1999; 72(3): 217-229.

[5] Tahmasebi M, Rahman R A, Mailah M, Gohari M. Roll movement control of a spray boom structure using active force control with artificial neural network strategy. Journal of Low Frequency Noise Vibration \& Active Control, 2013; 32(32): 189-202.

[6] He Y J, Qiu B, Yang Y F, Ma J. Deformation analysis and control of elastic deformation for spray boom based on finite element model. Transactions of the CSAE, 2014; 30(6): 28-36. (in Chinese)

[7] Wilkerson J B, Womac A R, Hart W E, Hong Y J. Sprayer boom instrumentation for field use. Transactions of the ASAE, 2004; 47(3): 659-666.

[8] Ramon H, Baerdemaeker J D. Spray boom motions and spray distribution: part 1, tion of a mathematical relation. Journal of Agricultural Engineering Research, 1997; 66(1): 23-29.

[9] Ramon H, Missotten B, Baerdemaeker J D. Spray boom motions and spray distribution, Part 2: Experimental validation of the mathematical relation and simulation results. Journal of Agricultural Engineering Research, 1997; 66(1): 31-39.

[10] Gil E, Gallart M, Balsari P, Marucco P, Almajano M P, Llop J. Influence of wind velocity and wind direction on measurements of spray drift potential of boom sprayers using drift test bench. Agricultural \& Forest Meteorology, 2015; 202: 94-101.

[11] Lardoux Y, Sinfort C, Enfält P, Sevila F. Test method for boom suspension influence on spray distribution, Part I: Experimental study of pesticide application under a moving boom. Biosystems Engineering, 2007; 96(1): 29-39.

[12] Lardoux Y, Sinfort C, Enfält P, Sevila F. Test method for boom suspension influence on spray distribution. ii. Validation and use of a spray distribution model. Biosystems Engineering, 2007; 96(2): 161-168.

[13] Sinfort C, Herbst A. Evaluation of the quality of spray distribution from boom sprayers in practical conditions. Eppo Bulletin, 2010, 26(1): 27-36.

[14] Drehmer LRC, Casas WJP, Gomes HM. Parameters optimization of a vehicle suspension system using a particle swarm optimization algorithm. Vehicle System Dynamics, 2015; 53(4): 449-474

[15] Zhao J, Cheng G, Ruan S, Li Z. Multi-objective optimization design of injection molding process parameters based on the improved efficient global optimization algorithm and non-dominated sorting-based genetic algorithm. International Journal of Advanced Manufacturing Technology, 2015; 78(9-12): 1813-1826.

[16] O'sullivan J A. Simulation of the behavior of a spray boom with an active and passive pendulum suspension. Journal of Agricultural Engineering Research, 1986; 35(3): 157-73.

[17] Cui L F, Xue X Y, Ding S M, Qiao B Y, Le F X. Analysis and test of dynamic characteristics of large spraying boom and pendulum suspension damping system. Transactions of the CSAE, 2017; 33(9): 61-68. (in Chinese)

[18] Cui L F, Xue X Y, Ding S M, Gu W, Chen C. Modeling and simulation of dynamic behavior of large spray boom with active and passive pendulum suspension. Transactions of the CSAM, 2017; 48(2): 82-90. (in Chinese)

[19] Abdelkefi A, Barsallo N. Nonlinear analysis and power improvement of broadband low-frequency piezomagnetoelastic energy harvesters. Nonlinear Dynamics, 2015; 83(1): 1-16.

[20] Calvo A, Deboli R. Whole Body Vibration (WBV): Comparison among field data and standard test track (ISO 5008) in different operative conditions, 2009.

[21] Viana F A C, Venter G, Balabanov V. An algorithm for fast optimal Latin hypercube design of experiments. International Journal for Numerical Methods in Engineering, 2010; 82(2): 135-156.

[22] Georgiou S D, Stylianou S. Block-circulant matrices for constructing optimal Latin hypercube designs. Journal of Statistical Planning \& Inference, 2011; 141(5): 1933-1943.

[23] Williamson D P, Shmoys D B. The design of approximation algorithms. Cambridge University Press, 2011.

[24] Pourtakdoust S H, Zandavi S M. A hybrid simplex non-dominated sorting genetic algorithm for multi-objective optimization. International Journal of Swarm Intelligence \& Evolutionary Computation, 2016; 5(3): $1-11$.

[25] Bolaños R I, Echeverry M G, Escobar J W. A multi-objective non-dominated sorting genetic algorithm (NSGA-II) for the Multiple Traveling Salesman Problem. Decision Science Letters, 2015; 4(4): 559-568.

[26] Rajabi-Bahaabadi M, Shariat-Mohaymany A, Babaei M, Chang W A. Multi-objective path finding in stochastic time-dependent road networks using non-dominated sorting genetic algorithm. Expert Systems with Applications, 2015; 42(12): 5056-5064.

[27] Milani A E, Haghifam M R, Hong W C S. A heuristic approach for multi objective distribution feeder reconfiguration: using fuzzy sets in normalization of objective functions. International Journal of Applied Evolutionary Computation, 2010; 1(1): 227-232. 